\title{
MOTHER TONGUE-BASED MATHEMATICS ILOKO LANGUAGE COMPETENCE OF GRADE I PUPILS IN BAUANG DISTRICT, DIVISION OF LA UNION
}

\author{
Eloisa A. Rivera \\ Department of Education, Philippines
}

\begin{abstract}
The study aimed to determine the Mother Tongue-Based Mathematics Iloko Language Competence of Grade I pupils of Bauang District, Division of La Union, which will serve as basis in developing a Mother Tongue-Based Mathematics Skillbook for Grade I. It identified the profile of the respondents along Socio-Economic Status, Ethnic Background, and Dominant Language Used as well as the level of competence in Mother Tongue-Based Mathematics of the Grade I pupils along Conceptual Skills, Analytical Skills, Computational Skills and Problem Solving Skills. It also determined the significant relationship between the respondents' profile variables and their Mother Tongue-Based Mathematics Competence as well as the strengths and weaknesses in Mother TongueBased Mathematics. The descriptive method of research was used in this study, and documentary analysis was utilized in gathering the needed data for the profile of the respondents. The study determined the level of competence of the respondents with a validated and reliable competence test which was constructed by the researcher. The results of the competence test were used as basis in the development of a Mother Tongue-Based Mathematics Skillbook. Based on the data gathered, the following were the salient findings of the study. A great majority of the respondents were Ilokanos who are of low socio-economic status. The pupils have High Competence in Conceptual and Analytical Skills and Moderate Competence in Computational and Problem Solving Skills. There existed a significant relationship between the respondents' ethnic background and their level of competence, as well as dominant language and their level of competence but there is no significant relationship between the respondents' socio-economic status and their level of competence in Mother Tongue-Based Mathematics. Conceptual Skills and Analytical Skills were discovered as the respondents' strengths while Computational skills and Problem Solving skills were discovered as their weaknesses. A validated skillbook was developed to address the identified weaknesses of the respondents.
\end{abstract}

Keywords: Analytical skills, Computational Skills, Conceptual Skills, Problem Solving Skills, Mother Tongue, Mother Tongue-Based Mathematics

\section{Introduction}

The $21^{\text {st }}$ century has been swamped with changes and challenges brought about by modern science and technology. Every aspect of human life has been through radical adjustments, and the international community has to adapt to these multitude of innovative technical and scientific undertakings.

To be abreast with these changes, and to be one with the modern world requires quality education which has become the modern man's primordial concern. Educators and school administrators have been geared to effect and sustain an efficient and effective paradigm shift to address the transformations in these contemporary times (Cristobal, 2014).

Quality education springs from quality instruction, and since Mathematics is an essential subject in any educational system, this subject must also be taught with competence and learned from excellent instruction. Mathematics has a major role not only in the advancement and innovations in science and technology. It too provides a solid foundation to the many aspects of man's daily activities, and it sheds light on the comprehension of complexities inherent in apparently quite simple situations (mathforum.org). Even in the simplest of man's undertakings, Mathematics is necessary so that everyone needs sufficient competence in the fundamental operations, as well as thorough understanding of its basic concepts. One needs the ability to compute numbers in any form and apply this in seeking solutions to any problem that may arise. As such, principles and standards for school Mathematics emphasize that students learn important Mathematical concepts or processes with understanding.

However, according to the Third International Mathematics and Science Study (TIMMS) which was carried out to students in the final year of secondary school undertaken in 2008, the Philippines had an average scale score of 355 in Advanced Mathematics courses. This was the lowest average achievement among the countries who

Corresponding Author: Eloisa A. Rivera/ mrserivera@gmail.com

$3^{\text {rd }}$ International Conference on Education, 20-22 April 2017, Kuala Lumpur, Malaysia 
participated in the study. This is a proof of the claim of many about the worsening levels of Mathematics and Science competency of Filipino students in international assessment tests. This they say, can be attributed to problems in the country's basic education sector which critics have described as being in an alarming state.

The aforementioned scenarios attest that the Philippine educational system has been hounded by a host of challenges posed by low-level achievements of learners particularly in the field of Science and Mathematics. One reason is that many children in the Philippines study Mathematics in a language they do not understand. Rinon (2015) said that the mother tongue of most Filipino children in the Philippines is neither Filipino nor English. Using these languages may not help the child carry out basic functions in his own contextual milieu. In class, listening to the strange sound and accent may at first enchant the child, but as the lessons become cognitively demanding he begins to feel disillusioned. The language barrier consequently stores up episodes of communication breakdowns between the teacher and the child as well as between the child and the unknown concept. Daunted by the feeling of not being able to communicate well in the foreign language, the child eventually drops out of school. Many children today leave school too early because the language of instruction has failed to facilitate their learning.

The K-12 Mathematics Curriculum has been crafted to provide the necessary solid foundation in Mathematics. But to further improve the dismal state of learning the subject in basic education, DEPED Order no. 31, s. 2009 has been implemented. This mandates the use of the Mother Tongue as a medium of instruction from Kindergarten to Grade III and is also taught as a subject. This DEPED Order is the Mother Tongue-Based Multilingual Education (MTBMLE) Program which has been carried out in 2012-2013. This program has been anchored from researches worldwide, which found out that top performing countries in International Mathematics and Science studies are those that always make reference to the language they already know and that in international Mathematics competitions, the high performing countries are those that allow their students to use their home language (http://conferences.cluteonline.com).

In Nolasco's Multilingual Education Primer (2011), it was also cited that young learners start from where they are and from what they already know. This could mean that the mother tongue is the primary tool in learning how to read and write as well as in learning about other subjects such as Mathematics, Science and Health, and Social Studies.

With the adoption of the MTBMLE Program in the Philippine Educational System, the stakeholders pin their hopes for an improvement in the quality of teaching and learning. But then, due to the novelty of the program, and the alacrity of its implementation, the dearth of instructional resources, references, books and materials for the use of teachers as well as learners especially in Mother Tongue Based Mathematics is a real problem the basic education teacher is beset with.

This is true, especially in Bauang District. As observed, the learners' materials used by the teachers and pupils are not enough to provide effective teaching-learning situation for the acquisition of basic skills in Mother TongueBased Mathematics. In fact, the learners' material provided by the DEPED in Mathematics for Grade I, Quarters 1 and 2 are written in English. This is the reason why teachers were having a hard time to supplement their lesson. The lack of additional references, learners' material and supplementary materials is one of the manifestations of difficulties in teaching Mother Tongue-Based Mathematics.

Considering the low performance in Mathematics and the shortage of references, learners' material and supplementary materials for Grade I pupils, the researcher has crafted a skillbook which can serve as a ready reference for the Grade I teacher, and as an authentic workbook for the learner.

\section{Theoretical Framework}

The Mother Tongue-Based Multilingual Education Program strongly argues that learners learn best when they are taught in a language that they understand. It is for this reason that teachers in the primary schools are now mandated to teach in the mother tongue, so that the objective to provide quality education can be achieved.

Relative to the notion on the native language as a means to facilitate learning, the Nativist theory (Shaffer, 2002) endorsed by Chomsky explains that humans are biologically programmed to gain knowledge. This theory posits that the human brain has an innate device, the LAD (Language Acquisition Device) which enables children to acquire a language at their earliest years from their homes and from the people they have grown with. This says that when the child goes to school for the first time, he already has a language to use when he communicates with his teachers and classmates. This language is his mother tongue, and this is the language which his teacher must utilize when he teaches inside the classroom, and even when he communicates with him beyond school time. This 
language will not only make him learn the lessons better, but will also make him feel welcome in the new environment, the affective factor which bears a positive influence to education in early childhood.

However, the Social Interactionist theory by Vygotsky stresses the environment as the most crucial influence in learning .This theory claims that the "significant others" in the learner's life have the biggest role to play when learners learn. This then points at the teacher as a crucial influence since he is the person who the learner associates with most of the time especially in the elementary grades. The teacher has to possess mastery of the subject matter, aside from his pedagogical expertise. This theory is substantiated by Skinner with his Behaviorist theory (Gleason and Ratner, 2009). This theory maintains that learning is enhanced by imitation and reinforcement. From this theory is the idea that learners learn from what is provided to them by the teachers, which they imitate and is retained in them through reinforcement. The teacher does not only explain the lesson well, but also gives the pupils a number of exercises and drills in order for the pupils to achieve mastery and retention of what has been learned.

The theory on Multiple Intelligences upheld by Gardner reiterates the idea that mathematical or logical intelligence is one of the eight intelligences that people can have. And similar to the other intelligences which are linguistic, spatial, bodily-kinesthetic, musical, interpersonal, intrapersonal and naturalist, a certain amount of one's knowledge and skill in Mathematics is innate. Yet, the great majority of this ability may come from learning.

Another theory that relates to this study is the Experiential Learning theory asserted by David Kolb (Duka, 2007). Kolb says that learners learn better and faster if the lessons being taught to them are within the sphere of their own experiences, enabling them to relate these lessons with what they already know and what they have gone through. A knowledge of the learner's experiences can then be the teacher's springboard when he explains the day's lessons. As such, the learners will have a better grasp of what the teacher is trying to elucidate upon them. This theory is very much related to the Constructivist theory which also argues that knowledge is constructed when the learner is able to draw ideas from his own experiences and connects them to new ideas encountered. Especially for lessons in Mathematics, pupils need to construct their own understanding of each mathematical concept, so that the primary role of teachers is not to lecture but to create situations which are familiar to these pupils that will foster their enthusiasm to build the necessary mental constructions.

The aforementioned theories explain that Mathematics can be learned by anyone, with the teacher's expertise of the subject matter and his appropriate pedagogy. However, teaching can become more effective with the teacher's personal knowledge of the pupils' background and experiences. The teacher's ability to speak the learner's language will bring about better comprehension and understanding, and his awareness of the pupils' experiences will enable him to utilize these as springboard for lessons or materials for drills and subsequent activities. As such, learning becomes interesting and is also attained with meaning.

\section{Conceptual Framework}

The Mother Tongue-Based Multilingual Education Program has been implemented with the conviction that it will upgrade the quality of education in the country. The DEPED has subscribed to the idea that when learners are taught in a language they know best, they will learn better, improving them not only on their communication skills but more on their cognitive skills. And this, experts say, is true to all the subject areas wherein the learners are supposed to be enrolled in. Consequently, Mathematics in the preschool is now being taught in the locality's language, and thus, it is presumed that the learners would become more competent in Math because they can understand the lessons quite well as the teacher now conducts the lesson in the language they have used since birth.

On the other hand, since ethnicity relates to cultural factors such as nationality, culture, ancestry, language and beliefs, this variable may also influence the learners' ability to grasp their lessons even in a Mathematics class. If the teacher talks in a language similar to the learners' language, making them learn lessons faster and better, then sharing with them the same culture, ancestry, and beliefs may also make the learners understand lessons easier. This can be so, because they will be able to relate the lessons with what the learners know and care about, since the teachers are aware of the learners' background, their lives, their practices and experiences.

Further, the learners' socio-economic status can also be a factor to consider with regard to the learners' aptitude to learn lessons, in Math, and even in all the subjects, because the financial capacity and the status in society of the learners' families can determine their exposure to factors that can enhance the development of their mental faculties. A financially - capable family can provide additional information from the recent advances in technology 
and children who are socially-adjusted encounter a variety of experiences which can enhance learning, while those who are less fortunate may just depend only on the basic information and limited experiences that a school may bring.

Along with the MTBMLE, the K-12 Mathematics Curriculum has been designed to foster the Mathematics Competence of primary school pupils. This is apportioned into five content areas which are Numbers and Numbers Sense, Measurement, Geometry, Patterns and Algebra, and Probability and Statistics. The major skills which these areas deem to exploit and consequently develop in every learner are conceptual, analytical, computational and problem solving skills. With this set of objectives in mind, teachers are compelled to realize that the curriculum provides a strong foundation in Mathematics literacy. More importantly, it postulates necessary concepts and life skills needed by Filipino learners as they proceed to the next stage in their life as learners and as Filipino citizens (K-12 Curriculum Guide in Mathematics).

Mathematical competence is gained with a thorough understanding of basic Mathematical concepts. But this would not be enough to further hone the different skills that the subject hinges on. A plenitude of exercises, drills and activities devised by the Mathematics teacher in accordance with the learners' needs, capacities and experiences would help sustain their interest which in the long run would reinforce their knowledge of the necessary Mathematical concepts and principles. Such would make the learners learn and appreciate the subject, and in an environment of familiarity and fun, the primary school pupils specially, would discover and develop their ability to conceptualize, analyze, compute and solve Math problems. Without their knowing, they would have refurbished their Mathematical skills.

Nevertheless, there is a dearth of mother tongue-based Mathematics references and materials that the Mathematics teacher in the primary grades can use nowadays. Ordoño (2012) says that, to attain quality education, there must be excellence in education service through the learners' printed and audiovisual materials. This thought has paved the way for the researcher to craft a Mother Tongue- Based Mathematics Skillbook for Grade I.

The research paradigm in Figure 1 explains further the flow of this study which leads to the formulation of the said skillbook. The Input-Process-Output (IPO) model was used as the researcher's guide.

The input variables are the profile of the respondents along socio-economic status, ethnic background, and dominant language used as well as the level of competence of Grade I pupils in Mother Tongue-Based Mathematics along conceptual skills, analytical skills, computational skills and problem solving skills.

The process includes the analysis of the profile of the respondents, the level of competence of Grade II pupils in Mother Tongue-Based Mathematics, the correlational analysis between the respondents' profile variables and Mother-Tongue Based Mathematics Competence. Included in the process as well is the identification of the students' strengths and weaknesses of the Grade II Pupils in Mother Tongue-Based Mathematics. These strengths and weaknesses were the bases for the researcher in the crafting of the Mother Tongue- Based Mathematics Skillbook for Grade I.

\section{Statement of the Problem}

The study aimed to determine the Competence in Mother Tongue-Based Mathematics of Grade I pupils of Bauang North and Bauang South Districts, Division of La Union, as basis in developing a Mother TongueBased Mathematics Sillbook for Grade I.

Specifically it sought to answer the following questions:

1. What is the profile of the respondents along:

a. Socio-economic status;

b. Ethnic background; and

c. Dominant Language used?

2. What is the level of competence in Mother Tongue-Based 
Mathematics of the Grade II pupils along:
a. Conceptual Skills;
b. Analytical Skills;
c. Computational Skills;
d. Problem Solving Skills?

3. Is there a significant relationship between the Respondents' Profile Variables and their Mother TongueBased Mathematics Competence?

4. What are the strengths and weaknesses in Mother Tongue-Based Mathematics of the Grade I pupils in Bauang North District and Bauang South Districts, Division of La Union?

5. What validated Skillbook in Mother Tongue-Based Mathematics can be proposed to enhance the Mathematics competence of the Grade I

Pupils?

\section{Importance of the Study}

This research will benefit several groups of people: the curriculum designers, teachers, pupils, stakeholders, the researcher herself and future researchers.

DEPED La Union, especially the Curriculum designers will gain insight on the crafting of learners' materials which will enhance the competence of pupils in Mother Tongue-Based Mathematics;

Grade I Math Teachers will be provided with the skillbook which they can utilize to supplement discussions of lessons and activities;

Grade I pupils will understand better the concepts and lessons in Mathematics I, hence enhance their mastery of Mathematical concepts and applications and will improve their competence in Mathematics I, as they are guided by the Skillbook which has been prepared in consideration of their level and weaknesses;

Stakeholders, especially parents and members of the community will be motivated to guide the learners in their lessons and other schoolworks because they too can already comprehend such, because these are now given in the Mother Tongue;

The researcher will be guided by the Skillbook to teach the learners better and make them realize the importance of Mathematics and the value of the native language;

And future researchers who can engage in a similar type of research will be encouraged to craft a Skillbook in the Mother Tongue, in order to facilitate learning and thereby develop the competence of the learners.

\section{Research Design}

The descriptive method of research was used in the study, as it aimed to gather data about existing conditions. Calmorin (2015) describes descriptive design as the collection of data to test hypothesis or to answer questions regarding the present status of a certain study. The study also used correlational analysis. Aiken (2002) defines correlational analysis as the use of statistical correlation to evaluate the strength of the relations between variables.

\section{Sources of Data}

The respondents in this study were the Grade I pupils of Bauang North and Bauang South Districts, Division of La Union for who were enrolled in the 10 schools in Bauang North District and 14 schools in Bauang South District. 
Stratified sampling was used to determine the sample from the population consisting of 1,509 pupils. The Slovin's formula at 0.5 margin of error was used to determine the sample size.

\section{Instrumentation and Data Collection}

Documentary analysis of the DEPED students' profile was used to gather the respondents' profile along socioeconomic status, ethnic background and dominant language used

The researcher-made Mathematics competence test based on the Basic Concepts of Grade I Mathematics as culled from DEPEd standards was also used by the researcher as the main data-gathering tool in the study. The 40-item test was divided into 5 areas of Grade I Mathematics: -Numbers and Number Sense, Geometry, Patterns and Algebra, Measurement, Statistics and Probability

Moreover, the test was made in accordance with Bloom's Taxonomy of Cognitive Skills for Mathematics which includes Conceptual, Analytical, Computational and Problem Solving Skills (Please see Appendix D).

\section{Tools for Data Analysis}

The data which were gathered, collated, and tabulated were subjected to statistical analysis and interpretation using the appropriate statistical tools.

For problem 1, frequency counts and percentages were used to determine the profile of the respondents along socio-economic status, ethnic background, and dominant language used.

For problem 2, the level of competence of the Grade I pupils in Mother Tongue-Based Mathematics was analyzed using frequency counts, percentages, and mean percentages. Frequency count was used to determine how many pupils fall in each item and respective rates were computed. The scores gathered were given corresponding descriptive equivalent.

For problem 3, the Pearson-Product Moment of Correlation (r) was used to determine the significance of relationship between respondents' profile variables and level of Mother Tongue-Based Mathematics Competence.

For problem 4, the strengths and weaknesses were deduced from the findings, particularly on the level of competence through statistical ranking. Areas with 61-100 percent were considered strengths; otherwise, 60 and below were considered weaknesses.

The MS Excel Data Analysis Tool and STATEXT were employed in treating the data.

\section{Ethical Considerations}

To observe and uphold ethical standards in the conduct of this research, conditions were strictly considered by the researcher.

A letter of communication was secured from the DEPED Division of La Union to serve as permission to the conduct of the study in the identified elementary schools. Likewise, a letter of communication was presented to the District Supervisors, principals and school heads to serve as permission to gather data pertinent to the study.

The respondents were not forced nor harmed in securing the needed data for this study and their names were not mentioned in any part of this research.

Reliability and validity measures of the research instruments were appropriately conducted, and documentation was properly observed for sourcing and referencing of materials.

\section{Findings:}

\section{Profile of the Respondents}


The first problem of the study focused on the profile of the respondents in Bauang North and Bauang South Districts, Division of La Union.

\section{Socio Economic Status}

Table 1 shows the socio-economic status of the respondents. Out of 316 respondents, two hundred six (206) or 65.19 percent belonged to families within Low-Socio Economic Status, eighty nine (89) or 28.16 percent belonged to Middle-Socio Economic Status, and twenty-one (21) or 6.65 percent belonged to High SocioEconomic Status. This implies that most of the respondents were living within the poverty threshold. This means that the families cannot buy at all times the basic needs for living. This is evident since the occupation of most of the parents of the respondents as manifested in the DEPED Profile in Bauang North and Bauang South Districts are farming, fishing, or none at all. This is parallel to the data from the National Statistics Coordination Board (NCSB), which also states that when the economic

Table 2. Distribution of Respondents According to Socio-Economic Status

Socio-Economic

Status
Frequency
Percentage

$(\%)$

$\begin{array}{lcr}\text { Low } & 206 & 65.19 \\ \text { Middle } & 89 & 28.16 \\ \text { High } & 21 & 6.65 \\ \text { Total } & & 100\end{array}$

status of a family is within the low level, the family is living within the poverty threshold. This means that a family of five can be considered extremely poor if it is earning Php 5,458 monthly or just enough to provide food on the table. This is similar to the finding of Sicat (2015) revealing that almost $75 \%$ of the Filipinos are living within poverty threshold. This is the main reason of high dropout rates, and illiteracy. This finding also runs parallel to a DEPED report (2017) which revealed that poverty is one of the hindrances in the educational success of Filipino learners.

Further, a report of the National Targeting System of the DSWD (2016) stressed that there are around 2, 951 household living within the poverty threshold in the Municipality of Bauang. Barangay Pilar had the highest poverty incidence with 117 out of 161 household surveyed as poor.

\section{Ethnic Background}

Table 3 reveals the distribution of the respondents according to their Ethnic Background. The Table reveals that three hundred five (305) or 96.52 percent of the total number of respondents are of Ilokano ethnicity, nine (9) or 2.85 percent are Tagalog, one (1) or 0.32 percent has Bikol as his ethnic background, and one (1) or 0.32 percent has Ifugao as his ethnic background. This implies that tribal communities are scattered across the archipelago even in La Union. Filipinos are divided geographically and culturally and they are recognizable by distinct traits, dialects and ethnic background.

The Table also gives a general impression that majority of the respondents are of Ilokano ethnic background. It means that most pupils in Bauang North and Bauang South Districts are culturally recognizable as Ilokanos. This finding runs parallel to the 2007 Census Population and National Targeting System of the DSWD (2016) revealing that 95 percent of the people in Bauang have Ilokano as their ethnic background and the remaining 5 
percent are of different ethnicity such as Bikol, Bisaya, Cuyunon, Hiligaynon, Kapampangan, Maranao, Maguindanao, Pangasinan, Tausug, Tagalog, Waray, Ifugao and others.

Table 3.Distribution of Respondents According to Ethnic Background

\begin{tabular}{lcc}
\hline Ethnic Background & Frequency & $\begin{array}{c}\text { Percentage } \\
(\%)\end{array}$ \\
& & 0.32 \\
Bikol & 1 & 96.52 \\
Ilocano & 305 & 2.85 \\
Tagalog & 9 & 0.32 \\
Ifugao & 1 & 100 \\
Total & 316 & \\
\hline
\end{tabular}

\section{Dominant Language Used}

Table 4 presents the distribution of the respondents according to Dominant Language Used. Out of 316 respondents, two hundred ninety-six (296) or 93.67 percent used Iloko as their dominant language while the remaining twenty (20) or 6.33 percent used Tagalog as their dominant language. This is understandable since majority of them have Ilokano ethnic background. This implies that the pupils used Iloko as their dominant language.

The finding is in support to the 2015 Census of Population which discloses that the Municipality of Bauang has a population of 69,837 and the dialect spoken by majority of the people is Ilokano, although there are other minor dialects such as Tagalog and Pangasinense used by the residents. English is also understood by many but is not widely spoken.

Table 4.Distribution of Respondents According to Dominant Language

\begin{tabular}{lcc}
\hline Dominant & Frequency & $\begin{array}{c}\text { Percentage } \\
(\%)\end{array}$ \\
Language & & 93.67 \\
Iloko & 296 & 6.33 \\
Tagalog & 20 & 100 \\
& 316 & \\
\hline
\end{tabular}

\section{Level of Competence of the Respondents in Mother Tongue-Based Mathematics}

The succeeding tables present the level of Mother Tongue-Based competence of the respondents in Bauang North and Bauang South Districts, Division of La Union along conceptual skills, analytical skills, computational skills, and problem-solving skills.

\section{Conceptual Skills}

Generally,the level of Mother Tongue-Based Mathematics Competence of the pupils along conceptual skills has a grand mean of 71.52 percent of correct answers which means that they have High Competence in conceptual skills. This means that the respondents have mastered the concepts, definitions, terms, descriptions and other facts in 
Mathematics. The finding is consistent with the K-12 Curriculum Guide in Mathematics, which holds that concepts are mastered first since these start the acquisition of learning. Rosete (2006) also stressed that conceptual skills are very important because these serve as the foundation of Mathematics skills.

Numbers and Numbers Sense ranks the highest with 76.90 percent of correct answers. This means that the pupils have mastered the basic mathematical terms, definitions and concepts

Table 5. Level of Competence of the Respondents along Conceptual Skills

\begin{tabular}{|c|c|c|c|}
\hline Content Areas & Percentage (\%) & $\begin{array}{l}\text { Descriptive } \\
\text { Equivalent }\end{array}$ & Rank \\
\hline $\begin{array}{ll}\text { 1. } & \text { Numbers and } \\
\text { Number Sense }\end{array}$ & 76.90 & High & 1 \\
\hline 2. Geometry & 73.42 & High & 2 \\
\hline $\begin{array}{c}\text { 3. Patterns and } \\
\text { Algebra }\end{array}$ & 67.41 & High & 5 \\
\hline 4. Measurement & 70.57 & High & 3 \\
\hline $\begin{array}{l}\text { 5. Statistics and } \\
\text { Probability }\end{array}$ & 68.99 & High & 4 \\
\hline Mean & 71.52 & High & \\
\hline
\end{tabular}

of whole numbers. They are familiar with mathematical terms, definitions and descriptions necessary in learning number facts. This finding is similar to the findings of various researches such as that of Villareal (2009) which revealed that the Grade V pupils in San Fernando District II have High Competence in whole numbers. Ducusin (2011) also found out that the pupils have initially mastered the basic concepts on whole numbers and the pupils are highly capable of reading and writing whole numbers, determining place value and rounding off numbers. Similarly, Sagun (2001) also revealed that Grade V pupils had mastery and competence on the basic concepts of whole numbers. The National Council of Mathematics (2008) also reported that almost all students demonstrate mastery of basic number facts.

On the other hand, the finding is in contrast to that of Novida (2005), revealing that Grade III pupils of Candon City Division have not mastered the very basic concepts on whole numbers including the concepts of the four fundamental operations. The finding is also in contrast to that of Manzano (2004), revealing that the students performed low in Mathematics, especially in mastering concepts of whole numbers. Similarly, the study of Rizalde (2012) revealed that the students have poor performance in basic concepts of real numbers, ratio and proportion, and recognizing and naming fractions. Culaste (2011) also stressed that the Mathematics competence of the pupils are below average level in terms of numerical comprehension, number sense estimation and procedural calculation.

The Table also shows that Patterns and Algebra ranks the lowest among the conceptual skills with 67.41 percent of correct answers. This implies that the pupils are having difficulty in mastering concepts along patterns and algebra since it requires actual application of basic number patterns and figures. This is similar to the study of Rodriguez (2010) revealing that students performed weak in Algebra especially in linear patterns.

\section{Analytical Skills}

Table 6 shows the level of competence of the respondents along analytical skills.

Generally, the pupils have High Competence in analytical skills with a mean of 64.87 percent of correct answers. This implies that the pupils are good in comprehension and analysis of mathematical

Table 6.Level of Competence of the respondents along Analytical Skills 

District, Division of La Union

\begin{tabular}{|c|c|c|c|}
\hline Content Areas & $\begin{array}{c}\text { Percentage } \\
(\%)\end{array}$ & $\begin{array}{l}\text { Descriptive } \\
\text { Equivalent }\end{array}$ & Rank \\
\hline $\begin{array}{ll}1 . & \text { Numbers } \\
\text { and } & \text { Number } \\
\text { Sense } & \end{array}$ & 65.82 & High & 2.5 \\
\hline 2. Geometry & 66.14 & High & 1 \\
\hline $\begin{array}{l}\text { 3. Patterns and } \\
\text { Algebra }\end{array}$ & 63.29 & High & 4.5 \\
\hline $\begin{array}{l}4 . \\
\text { Measurement }\end{array}$ & 65.82 & High & 2.5 \\
\hline $\begin{array}{l}\text { 5. Statistics } \\
\text { and } \\
\text { Probability }\end{array}$ & 63.29 & High & 4.5 \\
\hline Mean & 64.87 & High & \\
\hline
\end{tabular}

equations and problems. This could be attributed to the adaptation of the word problems to the local context.

Geometry, the subject which requires more analysis and probing, ranks the highest with 66.14 percent of correct answers along analytical skills. This implies that the pupils received more exposure on reasoning and on analyzing figures in Geometry. This is true since Geometry focuses much on analyzing shapes and illustrations of different figures. This finding negates the finding of Carreon (2009), that the Grade V pupils were moderately competent in geometry. Sagun (2001) also revealed that Grade V pupils in the private schools in San Fernando La Union, were competent in Geometry. Similarly, Novida (2005) also revealed that Grade III pupils show near mastery in spatial figures.

However, the finding negates that of four researches along the same field. Ducusin (2011), found out that Grade V pupils still lack the basic analytical skills to illustrate geometric figures. Ducusin's finding is similar to the study of Villareal (2009) which revealed that the respondents have fairly adequate skills in working with spatial figures. Similarly, the finding of Rodriguez (2010) revealed that her respondents have difficulty in illustrating figures. And Carreon (2009) also revealed that the students are weak in application and analysis in factoring, decimals and Geometry.

Although described as high competence, Patterns and Algebra and Statistics and Probability rank the lowest among analytical skills which both marked 63.29 percent of correct answers. This is similar to the study of Carreon (2009), revealing that the pupils have moderate competence in statistics and graphs but they experience difficulty in interpreting it. Similarly Millares (2001) also found out that the pupils are moderately competent in patterns because more exercises, drills and exposure have been provided for the pupils. However, they are weak in interpreting graphs. The finding of Novida (2005) also revealed that interpreting graphs is the error commonly committed by the pupils hence considered to be the least mastered competency.

In contrary to the present finding, Ducusin (2011) found out that graphs and number patterns are the areas which rank the highest. This means that the pupils are very good in reading and interpreting graphs and analyzing number patterns. Sagun (2001) also revealed that the pupils were excellent in constructing and interpreting graphs.

\section{Computational Skills}

Table 7 shows the competence of the respondents along computational skills.

Generally, the level of Mother Tongue Based Mathematics Competence of the respondents along computational skills has a grand mean of 60.13 percent of correct answers. This means that the pupils have Moderate Competence in terms of their computational skills. This implies that the pupils are capable of performing mathematical operations. This also means that the pupils are able to solve problems involving Numbers and Number Sense, Patterns and Algebra, Geometry, Measurement, and Statistics, but they have not fully mastered such competency.

Statistics and Probability ranks the highest with 65.82 percent of correct answers. This means that the pupils understand better the basic computation skills when these are translated in graphs. This is similar to the study of De Castro (2005), which showed that the Grade V pupils are very good in computation especially in graphs. Ledda 
(2006) also revealed that the pupils are more interested and performed better in statistics and graphs than in the other areas.

Numbers and Number Sense ranks the lowest with 55.06 percent of correct answers. This means that the pupils had not fully mastered the computational skills on this area which includes the two basic operations-addition and subtraction, and fractions. This shows that the

Table 7. Level of Competence of the Respondents along Computational Skills

\begin{tabular}{lccc}
\hline Content Areas & $\begin{array}{c}\text { Percentage } \\
(\%)\end{array}$ & $\begin{array}{c}\text { Descriptive } \\
\text { Equivalent }\end{array}$ & Rank \\
\hline $\begin{array}{l}\text { 1. Numbers and } \\
\text { Number Sense }\end{array}$ & 55.06 & Moderate & 5 \\
$\begin{array}{l}\text { 2. Geometry } \\
\text { 3. Patterns and }\end{array}$ & 59.81 & High & 3 \\
Algebra & 63.29 & Moderate & 2 \\
4. Measurement & 57.91 & Moderate & 4 \\
5. Statistics and & 65.82 & High & 1 \\
Probability & 60.13 & Moderate & \\
\multicolumn{1}{c}{ Mean } & &
\end{tabular}

pupils were not fully equipped with basic computational skills needed for the subject. The finding is in line with the finding of Rivera (2009), when she found out that majority of the pupils manifest high level difficulty in their computation skills especially on fractions. Similarly, Villareal (2009) also found out that the pupils are poor in performing operations involving fractions and decimals since they have low mastery in all topics under rational numbers. Novida (2005) also mentioned that the pupils had inadequate knowledge and skills working with ratio, fractions and decimals. Rodriquez (2010) likewise revealed that topics on rounding off numbers, place value and value of numbers and mastery of the basic operations were neglected and not emphasized. Manzano (2004) also found out that the students performed low in Mathematics particularly in the computation of the four fundamental operations. This finding runs parallel to the study of Tamayo (2005) revealing that the pupils are weak in computational skills on the four fundamental operations. Further, Ducusin (2011) revealed that the performance of the Grade $\mathrm{V}$ pupils in rational numbers is near mastery which means that the pupils still have misconceptions on operations of fractions and decimals.

\section{Problem Solving Skills}

Table 8 illustrates the level of competence of the respondents along problem solving skills.

Generally, the level of Mother Tongue-Based Mathematics Competence along problem-solving skills has a grand mean of 46.20 percent of correct answers which means that the respondents have Moderate Competence in problem solving skills. This means that the pupils are capable of analyzing and solving Mathematics problems especially that these are adopted to the local context. It can be inferred from the finding that the respondents in Bauang North and Bauang South Districts can analyze, solve and interpret word problems. This is rooted from their high competence in analytical skills and moderate competence in computational skills, since a good foundation of analytical and computational skills are necessary in solving word problems.

Statistics and Probability ranks the highest with 49.68 percent of correct answers. This implies that the pupils are more interested to solve problems in graphs since this area ranks also the highest in computational skills. This means that a good foundation in computational skills will lead to better competence in problem solving skills. This is similar

Table 8.Level of Competence of the Respondents along Problem Solving Skills

\begin{tabular}{llll}
\hline Content Areas & $\begin{array}{l}\text { Percentage } \\
(\%)\end{array}$ & $\begin{array}{l}\text { Descriptive } \\
\text { Equivalent }\end{array}$ & Rank \\
\hline 1.Number and Number & 45.57 & Moderate & 4 \\
Sense & & & 2 \\
2.Geometry & 49.37 & Moderate & 3 \\
3.Patterns and Algebra & 45.89 & Moderate & \\
\hline
\end{tabular}




\begin{tabular}{llll}
\hline 4.Measurement & 40.19 & Low & 5 \\
5.Statistics and & 49.68 & Moderate & 1 \\
$\begin{array}{l}\text { Probability } \\
\text { Mean }\end{array}$ & 46.20 & Moderate & \\
\hline
\end{tabular}

to the finding of Carreon (2009) that pupils are very good in problem solving involving tables and graphs. Similarly, De Castro (2005) also mentioned that the pupils have high competence in interpreting graphs and solving problems involving graphs.

It is also noticeable that measurement ranks the lowest with 40.19 percent of correct answers. This implies that most of the pupils find it difficult to solve word problems involving measurement. This can be attributed to the conversion factors and lack of actual application like actual measuring and manipulating concrete materials. This is the reason why real understanding of concepts was not attained. This is similar to the finding of Novida (2005), that measurement is one of the common errors of the Grade III pupils in Candon District. The pupils find difficulty in problem solving involving perimeter, area and measures of time. Ducusin (2011) also found out that the pupils show near mastery in measurement. This means that most of the pupils find it difficult to solve problems in measurement. Likewise, the finding is similar to Villareal's (2009), that the pupils had great difficulties in problem solving involving measurement. This is also comparable to the finding of Sagun (2011) that the pupils had great difficulty in problems involving perimeter, area and volume.

Conceptual Skills received the highest mean percentage among the four (4) skills. This implies that concepts are learned first since these serve as the foundation of all the other skills. However it is also noticeable that among the four (4) skills, Problem Solving Skills received the lowest mean. This is due to the fact that this skill requires more rigorous analysis and computation before one can actually come up with an approach to the problems and eventually to a correct solution. The finding is similar to that of Culaste (2011) that the Grade VI pupils showed difficulty in applying knowledge and changing preferences in order to solve a problem. Rivera (2010), also revealed that students have minimum competence in problem solving which is similar to the finding of Rosete (2006) which found out that most of the respondents did poorly in solving problems. The National Council of Mathematics (2008) also reported that almost all students encountered difficulty in mathematical problems. The pupils used inappropriate solution, and committed many computational errors.

\section{Correlation Between Respondents' Mother-Tongue Based Mathematics Competence and their Profile Variables}

Socio-economic status has negligible significant correlation to conceptual skills, analytical skills, computational skills and problem solving skills. This means that a pupil who has high socio- economic status does not automatically have a mastery of basic skills in mathematics. There are pupils who belong to the lower class who actually perform better than those who belong to the upper class of the society. This is similar to the finding of Millares (2001) that socio-economic circumstances do not have significant effect on the individual's choice and pursuit of a career.

A documentary also from GMA Reporters' Notebook says that pupils who are deprived of material wealth persevere a lot in pursuing education. Similarly, Gabriel (2012) also discovered that socio-economic status had a very small correlation with the Mathematics proficiency of pupils.

The Table also shows that ethnic background has substantial significant correlation to problem solving skills but not to conceptual, analytical and computational skills. This implies that a learner whose ethnic background is Ilokano has higher competence in Mother Tongue-based Mathematics, especially in problem solving skills. It implies that when a learner grows in the language he is exposed to, he is able to master it. This is also understandable since the pupils understand the language of the word problem. This implies further that the focus of the understanding is on how to solve the problem. This is in contrast when the problem is in English because the pupils have to focus on understanding both the content and the language. The finding is also in support to the Mother Tongue-Based Multi-Lingual Education (MTB-MLE) - a part of the K-12 basic education reform program which provides a strong foundation in Mathematics literacy and creates a smoother path to acquire basic mathematics skills. The Department of Education (DEPEd) also affirms that using language at home (MTB-MLE) inside the classroom during the early years of schooling produces better and fast learners. 
Also, it is noticeable that ethnic background has a significant but negligible correlation to conceptual skills. This means that learners who have Ilokano as their ethnic background do not automatically have higher competence on conceptual skills. This is so because the understanding of mathematical concepts is not dependent on ethnicity. There are concepts in Mathematics which cannot be translated in Iloko.

Moreover, ethnic background has also significant but low correlation to computational skills. This implies that ethnic background has minimum connection to computational skills. This means that ethnic background minimally affects the way pupils compute different number patterns. Since the Language used is Iloko, they are able to understand in their context.

Dominant language used has substantial significant correlation to analytical and problem solving skills but not to conceptual and computational skills. This implies that when the dominant language used and the medium of instruction are the same, significant learning takes place especially in analysis and problem solving. It is a fact that language used in class affects learning.

This finding is in consonance with what is stipulated in DEPEd order no. 74 s. 2009, that children learn best in a language that is familiar to them. Although children can learn a language other than their mother tongue, they learn best - especially in the early years - in an environment in which the language used to teach is also one they speak in their home, with their parents, their siblings, and friends. This is especially true in environments where children have little or no exposure to a second or foreign language. Moreover, since the school is a new social environment to children starting their education, learning in a mother tongue language also helps to ease this transition, providing a bridge from the "known" to the "unknown."

Also, there is a significant but low correlation between dominant language used and conceptual skills and dominant language used and computational skills. This implies that there is really minimum connection between dominant language used and conceptual and computational skills. This is similar to the finding in the correlation between ethnic background and conceptual skills and computational skills. It then implies that language used minimally affects the understanding and manipulation of mathematical skills and algorithms.

\section{Findings}

The following are the salient findings of the study.

1. A great majority of the respondents were Ilokanos who are of low socio economic status.

2. The pupils had High Competence in Conceptual and Analytical Skills and Moderate Competence in Computational and Problem Solving Skills.

3. There existed a significant relationship between the respondents' ethnic background and their dominant language but not with respondents' socio-economic status to the Level of Competence in Mother TongueBased Mathematics, to their ethnic background, dominant language and socio-economic status.

4. Conceptual Skills and Analytical Skills were the respondents' strengths while Computational skills and Problem Solving skills are their weaknesses.

5. A validated Skillbook was developed to address the identified weaknesses of the respondents.

\section{Conclusions}

In the light of the above-cited findings, the following conclusions were drawn:

1. The Grade II pupils are Ilokano who come from below average class of families

2. The Grade II pupils are good in Mathematics.

3. The pupils' ethnic background and dominant language used influence their Mathematical skills.

4. The pupils' skills in Computation and Problem Solving need enhancement.

5. The validated Skillbook is an instructional material that can be used as reference of teachers, or as a workbook for the learners.

\section{Recommendations}

Based on the conclusions of the study, the researcher recommends the following:

1. Teachers and Grade I pupils should adopt and use the Skillbook to improve the mathematical competence of the pupils and to equip them with the needed skills especially in problem solving and higher-order thinking. 
2. A regular assessment of the competence level of the pupils in Mother Tongue-Based Mathematics should be conducted.

3. A parallel study should be undertaken in all the other subject areas to find out the difficulties from the implementation of the MTB-MLE program in order that these could be addressed the soonest.

4. Also, parallel studies should be undertaken in order to encourage teachers to design and craft relevant and authentic instructional materials.

5. Continuous seminars, trainings, and workshops in the utilization and pedagogy using the Mother Tongue should be undertaken to enhance the linguistic and pedagogy skills of Basic Education Teachers. 


\section{References:}

Calderon, J.F and E.C Gonzales (2005). Research Methods and Thesis Writing. Quezon City: Rex Book Store Inc.

Calmorin, L.P and M. A. Calmorin (2003). Research Methods and Thesis Bookstore, Inc.

Writing. Quezon City: Rex

Duka, D.D. (2007). Lincensure Examination for Teachers 4th Edition. Manila City: Manila Review Center Institute.

Department Order \# 31 series of 2009

Department Order \#74 series of 2009

Double Exposure in Mathematics; a Glimpse of Mother Tongue First. Department of Education

K-12 Curriculum Guide as of January 2012

National Targeting System of DSWD 2016.

National Statistic Office 2007 Census Population

Multi-Lingual Education Primer 2011

Cristobal, Joseph M. Capabilities and Needs of the Faculty of Lorma Colleges along Instruction, Research and Instruction: Basis for a Training Program. Master Thesis. Saint Louis College. San Fernando City La Union. 2014

Carreon, Rowena D. Activity Book in Math V. Masters Thesis. Don Mariano Marcos Memorial State University, San Fernando City, La Union. 2009.

Dacanay, Rosemarie C. Basic Learning Skills of Preschoolers in Sta. Lucia District: Basis for a Learning Activity Package. Masters' Thesis. Saint Louis College.San Fernando. City La Union. 2011

De Castro, Sally L. Worksheets as Aids in Enhancing the Mathematical Abilities of Grade V Pupils. Masters' Thesis. Don Mariano Marcos Memorial State University, Agoo Campus. 2005

Ducusin, Rosalie M. Mathematics Performance and Personal Attributes of Grade V pupils: A basis for an Instructional Package. Masters’ Thesis. Saint Louis College. San Fernando City La Union. 2011.

Novida, Novelita C . Proposed Worktext in Elementary Mathematics III. Masters' Thesis. Saint Louis College, San Fernando City, La Union. 2005.

Ragma, Feljone. G. Competence of Mathematics Teachers in the Private Secondary Schools in San Fernando City, La Union: Basis For Two-Pronged Training Program. Masters’ Thesis. Saint Louis College, San Fernando City, La Union. 2011.

Rinon, Bernardita B. Teaching Literature in the Mother Tongue: Its Impact on the Learning Process and Appreciation of One's Culture. Published. Bicol University: 2011. 